\title{
Risk Analysis of Dynamic Water Level Setting of Reservoir in Flood Season Based on Multi-index
}

\author{
Zhenyu Mu \\ Wuhan University \\ Xueshan Ai ( $\nabla$ xsai@whu.edu.cn ) \\ Wuhan University https://orcid.org/0000-0002-4471-3307 \\ Jie Ding \\ Wuhan University \\ Kui Huang \\ Guangxi Electric Power Dispatching and Control Center \\ Senlin Chen \\ Wuhan University \\ Jiajun Guo \\ Wuhan University \\ Zuo Dong \\ Wuhan University
}

\section{Research Article}

Keywords: Flood free period, Flood season segmentation, Multi-order MCMC, Discharge, Power generation benefit, Risk rate

Posted Date: February 9th, 2022

DOI: https://doi.org/10.21203/rs.3.rs-1311268/v1

License: (c) (1) This work is licensed under a Creative Commons Attribution 4.0 International License.

Read Full License 


\title{
Risk analysis of dynamic water level setting of reservoir in flood season based on multi-index
}

\author{
Zhenyu $\mathrm{Mu}^{1}$, Xueshan $\mathrm{Ai}^{1,2}$, Jie Ding ${ }^{1}$, Kui Huang ${ }^{3}$, Senlin Chen ${ }^{1}$, Jiajun Guo ${ }^{1}$, Zuo Dong ${ }^{1}$
}

Abstract The long-term operation of the reservoir at the flood limit water level in the flood season is not conducive to the exertion of the comprehensive benefits of the reservoir, especially in the flood free period, the operation of the reservoir at the flood limit water level will cause a certain waste of resources. On the one hand, with the continuous improvement of the forecast accuracy, the effective forecast period of flood forecast will continue to extend, when there is excess water in the flood free period, the water level can be raised instead of abandoning the water to increase the benefit of power generation. If there is a flood, it can be discharged within the effective forecast period of flood forecast to make the water level drop back to the flood limit level, so as to ensure the safety of flood control; On the other hand, affected by the forecast uncertainty and other factors, the higher the operating water level in the flood free period, the greater the risk that the water level can return to the flood limit water level through discharge, and the decision-making based only on the power generation benefit and risk rate is difficult to deal with the possible large-scale flood events in the future. This study proposes a dynamic water level decision-making system in flood free period. The system considers three factors: power generation benefit, discharge in the effective forecast period of flood forecast and risk rate. It can provide decision-makers with a variety of decision-making schemes and screen the optimal scheme, thus improving the operational benefit of

\footnotetext{
Ai Xueshan

$\underline{\text { xsai@whu.edu.cn }}$
}

\footnotetext{
State Key Laboratory of Water Resources and Hydropower Engineering Science, Wuhan University, 430072, Wuhan, China.

Hubei urban construction vocational and technological college, Wuhan University, 430205, Wuhan, China.

Guangxi Electric Power Dispatching and Control Center, 530023, Nanning, China.
} 
hydropower station in flood season and reducing flood control risk. Firstly, historical data and various flood season staging methods are used to divide the flood season into multiple sub-seasons, and then the maximum inflow process in the effective forecast period of flood forecast in each subseason is selected. According to this inflow process, the upper limit of operating water level in the flood free period of each sub-season is determined based on the reservoir discharge capacity, and the operating water level points and discharge ratio are discretized, Then the multi-order Monte Carlo Markov chain (MCMC) and Monte Carlo method are used to calculate the risk rate. Then, the scheme set is established by the three variables of power generation benefit, discharge ratio and risk rate. Finally, the weighted Topsis method is used to determine the optimal scheme. In the practical application, the influence of each risk factor on the risk rate and the influence of weight on the final decision are also compared and analyzed. This method has been verified in Youjiang reservoir in Yujiang River Basin. The main conclusions are as follows: (1) Combined with the discharge in the forecast period, the reservoir operating water level has a certain lifting space in the flood free period, which can effectively reduce the waste of resources. (2) In the discharge process in the forecast period, runoff forecast error and discharge error are the two factors that have the greatest impact on the risk rate, and the multi-order MCMC method effectively reflects the relationship between the adjacent periods of runoff forecast error, and its simulation process is closer to the reality. (3) Topsis with the combination of AHP and entropy weight method can fully consider the characteristics of power generation benefit, discharge ratio and risk rate, and it is effective to select the optimal solution from the set of non-inferior schemes. This method provides a new idea for determining the operating water level of the reservoir in the flood season.

Keywords Flood free period; Flood season segmentation; Multi-order MCMC; Discharge; Power generation benefit; Risk rate. 


\section{Introduction}

Hydropower is the most reliable, mature, stable and currently accounting for the largest proportion of clean energy and its development can help relieve the environmental problems caused by the shortage of traditional fossil energy and fuel consumption, and achieve carbon neutrality (Yüksel 2010; Liu et al. 2022; Moser et al. 2021). At the same time, due to the problem of low operation and management level in reservoir regulation, the efficient utilization of hydropower station and the development of key technologies play an important role in urgent research fields, and the selection of flood season operation decision and risk research is a significant research direction. On the one hand, with the continuous improvement of the forecast accuracy, the effective forecast period of flood forecast will continue to extend, when there is excess water in the flood free period, the water level can be raised instead of abandoning the water to increase the benefit of power generation. If there is a flood, it can be discharged within the effective forecast period to make the water level drop back to the flood limit water level (FLWL) so as to ensure the safety of flood control; On the other hand, affected by the forecast uncertainty and other factors, the higher the operating water level in the flood free period, the greater the risk that the water level can return to FLWL through discharge. At the same time, climate change is causing more extreme flood events (Reichstein et al. 2021), decisions made only based on power generation benefits and the risk rate calculated based on historical data are difficult to deal with large-scale flood events that may occur in the future. Under the trend of high-efficiency utilization of water energy, based on runoff forecast, it is of great research significance and value to formulate a dynamic water level setting method of reservoir in flood season, which can improve operation efficiency and avoid high risk, and take the possible extreme floods into account in the future.

Hydrological forecast has the characteristics of hourly rolling and dynamic updating: in each period, The forecast model is used to forecast the runoff in a certain forecast period $\mathrm{H}$ in the future based on the known hydrological information such as water storage capacity, rainfall observation 
and rainfall forecast; In the subsequent period, the runoff forecast will be dynamically updated in combination with the updated hydrological information (Zhao 2013). At the same time, due to the influence of factors such as model parameter error, the prediction error in each period of runoff prediction has a certain correlation. In order to describe this correlation, Copula function (Xu et al. 2021; Li et al. 2022; Dodangeh et al. 2020), Bayesian network ( $\mathrm{Lu}$ et al. 2020), Monte Carlo Markov chain (Hadfield 2010) and other methods have been applied to runoff simulation in recent years, theoretically, when the forecast period is long enough, inputting the hourly updated hydrological forecast into the operation model can update the operation decision hourly, so as to make full use of the hydrological forecast information and improve the benefits of the reservoir system (Zhao et al. 2011). At the same time, combined with the simulation of uncertain factors such as runoff forecast error, the possible risks of operational decision can be better analyzed, providing clear guidance for reservoir operation.

There is an interactive and competitive relationship between risk and power generation benefit, and its competition intensity will change with the change of sub-seasons (Yao, 2019). In order to describe the competition relationship between risk and benefit, it is necessary to divide the flood season into multiple sub-seasons, and adopt multiple FLWLs instead of a single constant value in the whole flood season (Fang et al. 2007; Yun and Singh, 2008). After analyzing and improving the existing research results, segmentation methods can be mainly divided into six categories: fractal, cluster analysis, change point analysis, fuzzy set analysis, projection pursuit and Fisher the optimal break up. For example, Liu et al (2011) used directional statistics (DS) method to divide the flood season of the Three Gorges, Pan (2018) et al proposed a quantitative measurement method Seasonal exceedance probability (SEP) to evaluate the flood season staging scheme. The above method can effectively carry out reliable flood season staging according to runoff, rainfall, flood information and other factors.

In order to make a decision by integrating risk and power generation benefit, many decisionmaking solutions have been applied. For example, Chen (2021) combined entropy weight method 
with Topsis method to evaluate flood risk and loss in southern China, making up for the lack of research on the comparison of flood risk and benefit loss; Li et al (2021) determined the benefit and risk index set of phased control of FLWL, and established a risk-benefit multi-objective collaborative decision-making model to solve the optimal decision-making, so as to effectively combine the benefit and risk; Xu et al (2020) established a two-stage stochastic optimization model to find a balance between water shortage and flood risk. The above methods effectively consider the risk and benefit factors. However, due to the particularity of risk indicators, it is difficult to measure their weight by objective methods, so it is necessary to add subjective factors in decision-making in order to find a better scheduling method.

The research shows that with the continuous improvement of forecast accuracy, short-term runoff forecast has been used in water resources management and other fields (Carpenter and Georgakakos 2001; Alizadeh et al. 2017), and the results of flood season segmentation method are also very fruitful, which provides a basis for the effective combination of risk and benefit in the process of reservoir operation. However, The existing results are still difficult to solve three major problems: Firstly, the existing studies often focus on flood risk, only coordinating benefits and risks by changing FLWL, but ignoring the waste of resources when the reservoir is maintained at FLWL in the flood free period; Secondly, affected by climate change the frequency of extreme weather is increasing, and the existing research lacks effective response measures for possible catastrophic floods in the future; Thirdly, the particularity of risk rate and other indicators is ignored when using objective methods for decision selection, which makes the final decision unreasonable.

To bridge the knowledge gaps, this paper proposes a decision-making system of optimal water level in flood season. The system considers three factors: power generation benefit, discharge in the effective forecast period of flood forecast and risk rate. It can provide decision-makers with a variety of decision-making schemes and screen the optimal scheme so as to improve the operating benefit of hydropower station in flood season and avoid flood control risk. In this method, we firstly use historical data and various flood season staging methods to divide the flood season into multiple 
sub-seasons, and then the maximum inflow process in the effective forecast period of flood forecast in each sub-season is selected. According to this inflow process, the upper limit of operating water level in the flood free period of each sub-season is determined based on the reservoir discharge capacity, and the operating water level points and discharge ratio are discretized, Then the multiorder Monte Carlo Markov chain (MCMC) and Monte Carlo method are used to calculate the risk rate, finally the weighted Topsis method is used to determine the best scheme. The influence of each risk factor on the risk rate and the effect of weight on the final decision are also compared and analyzed.

The remainder of this paper is organized as follows. Section 2 explains the establishment process and solution method of the optimal water level decision system in flood season. Section 3 describes the application of the method to the Youjiang reservoir in Yujiang River Basin. Section 4 presents the main results and analysis. Section 5 presents the conclusions.

\section{Methodology}

Affected by the uncertainty of flood in the flood season, in order to reduce the flood control risk of the reservoir itself and downstream, the water level is usually maintained near the FLWL in the flood season. On the one hand, in order to ensure the completion of flood control tasks, the FLWL of the reservoir is usually low and the water head available for power generation is less, so that the reservoir cannot give full play to its power generation capacity in the flood season, especially in the period without flood. On the other hand, Due to the limitation of reservoir discharge capacity and downstream flood control safety, the higher the operating water level in the flood free period, the more difficult it is to reduce the water level back to the FLWL in the effective forecast period, and the higher the risk. At the same time, in order to cope with the increasingly frequent extreme weather and extreme flood events, a certain space should be reserved on the basis of maximum safe discharge. Based on the above characteristics, this paper establishes an optimal water level 
decision-making system and optimal scheme determination method in flood free period in flood season. The details are given as follows.

Fig. 1 is the method frame diagram of this study.

\subsection{Flood season segmentation}

Under the condition of ensuring the dam safety and downstream flood control safety, the phased operation of the reservoir is not only an important measure to improve the benefits of the reservoir, but also the basic premise to determine and adjust the phased FLWL of the reservoir (Wang et al. 2007; Dong et al. 2007). In this paper, the circular distribution method (Fang et al. 2007), fuzzy statistical test method (Chen et al. 2003) and fuzzy set analysis method (Wang et al. 2020) are selected to divide the flood season, and then the rationality of staging results was analyzed based on regional hydrological and climatic conditions and historical flood data, and the flood season staging scheme was determined.

\subsubsection{Circular distribution method}

Assuming that the total number of days in the calculation period is $\mathrm{T}$, and the occurrence time and magnitude of the flood peak of the flood sample $i$ are $D_{i}$ and $Q_{i}$, respectively coordinate value of flood time without considering and considering flood magnitude $\left(x_{i}, y_{i}\right)$ is:

$$
\begin{aligned}
& \left(x_{i}, y_{i}\right)=\left\{\begin{array}{l}
\left(\cos \alpha_{i}, \sin \alpha_{i}\right), \quad \text { without considering flood magnitude } \\
\left(q_{i} \cos \alpha_{i}, q_{i} \sin \alpha_{i}\right), \quad \text { considering flood magnitude }
\end{array}\right. \\
& (\bar{x}, \bar{y})=\left(\sum_{i=1}^{N} x_{i} / N, \sum_{i=1}^{N} y_{i} / N\right)
\end{aligned}
$$

Where $N$ is the sample size; $\alpha_{i}=D_{i} \frac{2 \pi}{T}$ is the occurrence time of the flood $i$ (angle), $0 \leq \alpha_{i} \leq 2 \pi$.

Concentration period of flood in calculation period $\bar{\alpha}$ and concentration $r$ are respectively: 


$$
\begin{gathered}
\bar{\alpha}= \begin{cases}\arctan \bar{y} / \bar{x} & \bar{x}>0, \bar{y}>0 \\
2 \pi+\arctan \bar{y} / \bar{x} & \bar{x}>0, \bar{y}<0 \\
\pi+\arctan \bar{y} / \bar{x} & \bar{x}<0 \\
\pi / 2 & \bar{x}=0, \bar{y}>0 \\
3 \pi / 2 & \bar{x}=0, \bar{y}<0 \\
\text { 不定 } & \bar{x}=0, \bar{y}=0\end{cases} \\
\mathrm{r}= \begin{cases}\sqrt{\bar{x}^{2}+\bar{y}^{2}}, & \text { without considering flood magnitude } \\
\sqrt{\bar{x}^{2}+\bar{y}^{2}} / \bar{q}, & \text { considering flood magnitude }\end{cases}
\end{gathered}
$$

In which $\bar{q}$ is the mean of $\mathrm{N}$ sample flood peaks.

Concentration $\mathrm{R}$ in a circular distribution is a statistical index of describing concentration trend of $\alpha_{i}, 0 \leq r \leq 1$, and the closer $\mathrm{r}$ is to 0 , the more uniform the distribution of flood occurrence time is; The closer $r$ is to 1 , the higher the concentration of flood occurrence time in a certain area. The relationship between $\mathrm{r}$ and the standard deviation $\mathrm{s}$ of $\alpha_{i}$ is as follows:

$$
s=\sqrt{-2 \ln r}
$$

$s$ is an index indicating the discrete trend of flood occurrence time。 The starting and ending days $D_{1}$ and $D_{2}$ of the main flood season in the calculation period are respectively:

$$
\begin{gathered}
D_{1}=\frac{\bar{\alpha}-s}{2 \pi} T \\
D_{2}=\frac{\bar{\alpha}+s}{2 \pi} T
\end{gathered}
$$

\subsubsection{Fuzzy statistical test method}

According to the daily average flow data samples over the years, take the average daily runoff of many years as the threshold, calculate the cumulative sum of the runoff exceeding the indicator threshold and the quotient of the indicator threshold in each year, divide by the total number of years, and obtain the corresponding indicator value of each date:

$$
D_{t}=\left[\sum_{i=1}^{N}\left(Q_{i, t}-Q_{y}\right) / Q_{y}\right] / N
$$


$\overline{\text { Where } Q_{i, t} \text { is the average daily runoff on the day } t \text { of the year } i ; Q_{y} \text { is the multi-year daily average }}$ flow; $N$ is total years.

Select an appropriate positive number as the membership threshold. If the membership reaches or exceeds the threshold at a certain time, it is the member of the flood season. Other times can be classified into corresponding sub-seasons according to the membership degree of the main flood season.

\subsubsection{Fuzzy set analysis method}

Select the $N$-year daily average runoff data as the sample, and take the multi-year average runoff $Q_{T}$ as the sample standard value. When the average daily runoff is greater than $Q_{T}$, it is considered to enter the flood season. Count the start and end time of the flood season each year, obtain the daily coverage times $m_{i}$, and calculate the membership degree $U_{A}(\mathrm{t})$ of day $\mathrm{t}$, and $U_{A}(\mathrm{t})=\mathrm{m}_{i} / N$, finally draw the empirical membership function curve in flood season. The threshold $\lambda$ is determined according to experience. When the empirical membership of the period is greater than $\lambda$, it is considered that the period belongs to the main flood season. The start time $a_{1}$ and end time $a_{2}$ of the main flood season are determined in the figure. Then, the semi normal distribution function is used to fit the empirical membership function curve in flood season, fit the membership function curve and fitting parameters $b_{1}, b_{2}$, and the calculation formula is:

$$
\begin{gathered}
U_{A}(\mathrm{t})=\left\{\begin{array}{cc}
\exp \left[-\left(\frac{a_{1}-t}{b_{1}}\right)^{2}\right] & \mathrm{t}<a_{1}, b_{1}>0 \\
1 & a_{1} \leq t \leq a_{2} \\
\exp \left[-\left(\frac{t-a_{2}}{b_{2}}\right)^{2}\right] & \mathrm{t}>a_{2}, b_{2}>0
\end{array}\right. \\
b_{1}=\sqrt{-\sum_{i=1}^{a_{1}}\left(a_{1}-i\right)^{2} / \sum_{i=1}^{a_{1}} \ln u_{i}} \\
b_{2}=\sqrt{-\sum_{i=a_{2}}^{T_{0}}\left(i-a_{2}\right)^{2} / \sum_{i=a_{2}}^{T_{0}} \ln u_{i}}
\end{gathered}
$$


Where $T_{0}$ is the last time of flood season, and $u_{i}$ is the empirical membership in day $i$.

Draw the curve of fitting membership function. Keep the threshold $\lambda$ unchanged and determine the main flood season $A_{\lambda}^{\prime}=\left[a_{1}^{\prime}, a_{2}^{\prime}\right]$ in the figure. Where $a_{1}^{\prime}$ and $a_{2}^{\prime}$ are the starting and ending time of main flood season determined by the fitting curve of empirical membership function. The final main flood season can be obtained by taking $A_{\lambda}$ and $A_{\lambda}^{\prime}$ compromise values.

\subsection{Establishment of operating water level and discharge scheme}

\subsubsection{Upper limit of relative safe water levels in sub-seasons}

According to the historical flood data in a certain sub-season of the reservoir, take the excess downstream safety discharge as the flood rising point, count the water inflow data in each period of the forecast period before the rising point, and select the group with the largest total water inflow as $Q_{i n}=\left(Q_{i n, 1}, Q_{i n, 2}, Q_{i n, 3} \ldots, Q_{i n, \mathrm{~T}}\right)$

Considering the downstream flood control safety and reservoir discharge capacity, the maximum discharge $\left(Q_{\text {out }, t}^{\max }\right)$ of each period in the forecast period is defined as

$$
Q_{o u t, t}^{\max }=\min \left(Q_{a q}, Q_{x, t}\right)
$$

Where $Q_{a q}$ is safety discharge at the downstream flood control point, $Q_{x, t}$ is the reservoir maximum discharge in period $t$ according to the discharge capacity, and $Q_{x, t}=f_{z q}\left(Z_{t, c}\right), f_{z q}$ is discharge capacity curve, $Z_{t, c}$ is the initial water level in period t.

The water balance equation of each period is:

$$
\left\{\begin{array}{l}
V_{t, m}=V_{t, c}+\left(Q_{i n, t}-Q_{o u t, t}\right) \times T_{d} \\
V_{t, c}=V_{t-1, m} \\
Z_{t, m}=f_{z v}\left(V_{t, m}\right) \\
Z_{t, c}=f_{z v}\left(V_{t, c}\right)
\end{array}\right.
$$

Where $Z_{t, m}$ and $V_{t, m}$ are the end water level and end storage in period $\mathrm{t}, V_{t, c}$ is the initial storage in 
period t, $Q_{o u t, t}$ is outflow in period t, $f_{z v}$ is storage-capacity curve, $T_{d}$ is the unit time.

Let $Q_{\text {out }, t}=Q_{\text {out }, t}^{\max }$, and several water levels at the beginning of the forecast period are set for trial calculation until there is an initial water level so that the water level at the end of the forecast period $\left(Z_{T, m}\right)$ is exactly the FLWL $\left(Z_{x}\right)$, that is, under the premise of considering the downstream flood control safety and reservoir discharge capacity, discharging from this water level at the beginning of the forecast period can make the operating water level fall back to the FLWL just at the end of the forecast period, so this water level is recorded as the Upper limit of relative safe water level $Z_{\max }$.

\subsubsection{Discrete operating water level}

$N$ operating water level points are evenly dispersed based on the FLWL and the upper limit of relative safe water level in sub-seasons, which are recorded as: $Z=\left(Z_{1}, Z_{2}, \ldots, Z_{N}\right)$, and the upper and lower limits of each water level point are

$$
Z_{x}<Z_{i} \leq Z_{\max }
$$

\subsubsection{Discharge ratio setting}

In order to reserve a certain discharge space, the discharge can be reduced based on the maximum discharge $\left(Q_{o u t, t}^{\max }\right)$ in each sub-season, and the discharge ratio point is defined as $\alpha=\left(\alpha_{1}, \alpha_{2}, \ldots, \alpha_{M}\right)$, whose upper and lower limit constraints are:

$$
0<\alpha_{i} \leq 1
$$

At this moment the discharge in each period is:

$$
Q_{\text {out }, t}=\alpha_{i} Q_{\text {out }, t}^{\max }=\alpha_{i} \cdot \min \left(Q_{a q}, Q_{x, t}\right)
$$

Obviously $\alpha_{i}=1$ in the calculation of $Z_{\max }$. 


\subsection{Risk analysis}

\subsubsection{Risk factor identification}

Risk factors have an important impact on the occurrence of risk events, which are usually random. The identification of risk factors has an important impact on risk assessment (Jiang et al. 2018). Combined with the characteristics of reservoir flood control, this paper extracts three main risk factors and describes their probability distribution.

(1) Runoff forecast error

Runoff forecast error is a manifestation of the uncertainty of hydrological forecast. For the forecast and dispatching work, the early inflow runoff forecast work mostly forecasts the inflow in multiple subsequent periods at a fixed time and at a fixed interval, therefore, when simulating the runoff forecast error, the correlation between them at different forecast times in the prediction period should be considered (Zhang 2021). The forecast error in period $j$ of forecast work $i\left(e_{i, j}\right)$ is:

$$
e_{i, j}=\left(Q_{i, j}^{y}-Q_{i, j}^{s}\right) / Q_{i, j}^{s} \times 100 \%
$$

Where $Q_{i, j}^{y}$ and $Q_{i, j}^{s}$ are the forecast flow and observed flow in period $j$ of forecast work $i$.

The Markov chain is a stochastic model that describes a sequence of possible events wherein the probability of each event depends only on the state attained in previous events (Xu et al, 2021). In this paper the runoff series is simulated based on multi-order MCMC and the normal distribution of error in each period, and steps are as follows:

1) According to the forecast error samples, the error normal distribution in period $j$ is fitted, and $e_{j} \sim N\left(\mu_{j}, \sigma_{j}^{2}\right)$

2) The sample errors in each period are divided into different states. In this paper, the mean standard deviation classification method is used to divide the errors into five states, which are recorded as $S=(1,2,3,4,5)$, so the sample states in period $j$ of sample $i\left(S_{i, j}\right)$ are respectively: 


$$
\left\{\begin{array}{cc}
S_{i, j}=1, & e_{i, j} \leq \mu_{i}-1.1 \sigma_{i}^{2} \\
S_{i, j}=2, & \mu_{i}-1.1 \sigma_{i}^{2}<e_{i, j} \leq \mu_{i}-0.5 \sigma_{i}^{2} \\
S_{i, j}=3, & \mu_{i}-0.5 \sigma_{i}^{2}<e_{i, j} \leq \mu_{i}+0.5 \sigma_{i}^{2} \\
S_{i, j}=4, & \mu_{i}+0.5 \sigma_{i}^{2}<e_{i, j} \leq \mu_{i}+1.1 \sigma_{i}^{2} \\
S_{i, j}=5, & e_{i, j}>\mu_{i}+1.1 \sigma_{i}^{2}
\end{array}\right.
$$

3) Transition probability matrix calculation. The $i$-step transition matrix $\left(T M_{j}\right)$ is constructed by calculating the transition steps $f_{a, b}^{(j)}$ from one state $a$ (time $j$ ) to another state $b($ time $j+1)$ in the sample sequences:

$$
T M_{j}=\left[\begin{array}{cccc}
f_{1,1}^{(j)} & \mathrm{L} & \mathrm{L} & f_{r, 1}^{(j)} \\
f_{1,2}^{(j)} & \mathrm{L} & \mathrm{L} & f_{r, 2}^{(j)} \\
\mathrm{M} & \mathrm{M} & \mathbf{M} & \mathrm{M} \\
f_{1, r}^{(j)} & \mathrm{L} & \mathrm{L} & f_{r, r}^{(j)}
\end{array}\right]
$$

And $T P M_{j}$ can be estimated according to $T M_{j}$, as shown in Eq. (20) and (21):

$$
\begin{gathered}
T P M_{j}=\left[\begin{array}{cccr}
p_{1,1}^{(j)} & \mathrm{L} & \mathrm{L} & p_{r, 1}^{(j)} \\
p_{1,2}^{(j)} & \mathrm{L} & \mathrm{L} & p_{r, 2}^{(j)} \\
\mathrm{M} & \mathrm{M} & \mathrm{M} & \mathrm{M} \\
p_{1, r}^{(j)} & \mathrm{L} & \mathrm{L} & p_{r, r}^{(j)}
\end{array}\right] \\
p_{a, b}^{(j)}= \begin{cases}\frac{f_{a, b}^{(j)}}{\sum_{b=1}^{r} f_{a, b}^{(j)}}, & \sum_{b=1}^{r} f_{a, b}^{(j)} \neq 0 \\
0, & \sum_{b=1}^{r} f_{a, b}^{(j)}=0\end{cases}
\end{gathered}
$$

4) There are $T$ periods in the effective forecast period of flood forecast. If the start period is $j$, a random number $e_{1}$ satisfying the normal distribution of errors in period $j$ is generated, and $e_{1} \sim N\left(\mu_{j}, \sigma_{j}^{2}\right)$. Judge the state of $e_{1}$ according to Eq. (18), subsequently the states of the relative forecast errors $\left(S_{m}\right)$ are generated based on Monte Carlo method and state transition probability matrix, and $S_{m}=\left(S_{1}, S_{2}, \mathrm{~L}, S_{t}, \mathrm{~L}, S_{T}\right), S_{t} \in S$. We then obtain the simulation scenarios of the relative forecast errors processes $e_{m}=\left(e_{1}, e_{2}, \mathrm{~L}, e_{t}, \mathrm{~L}, e_{T}\right)$ based on uniform sampling within the error 
range of each state.

5) Take $Q_{i n}$ in section 2.2 as the forecast runoff series, and the observed runoff of each period $\left(Q_{i n, t}^{*}\right)$ is:

$$
Q_{i n, t}^{*}=Q_{i n, t} /\left(1+e_{t}\right)
$$

(2) Delay time of operation

Delay time of operation comes from the steps of flood forecast and approval of superior competent department before putting operations into force. Due to difficulties to obtain its probability distribution theoretically, we thus estimated it by triangular distribution, and the probability density function is:

$$
f(t)= \begin{cases}\frac{2(t-a)}{(b-a)(c-a)}, & a \leq t \leq c \\ \frac{2(b-t)}{(b-c)(b-a)}, & c \leq t \leq b \\ 0, & t<a, t>b\end{cases}
$$

Where $a, b$ and $c$ are the minimum, maximum and possible values of scheduling delay respectively.

To ensure safety and generate electricity as much as possible before the release time $\left(t<t_{z}\right.$, and $t_{z}$ is the simulation of delay time of operation), when the inflow flow is less than the maximum power generation flow, it shall be discharged by maximum generation flow $\left(Q_{f d, \max }\right)$, and if the inflow flow is greater than the maximum power generation flow, the minimum of the inflow $\left(Q_{i n, t}\right)$, safety discharge $\left(Q_{a q}\right)$ and the reservoir maximum discharge $\left(Q_{x, t}\right)$ shall be taken for discharge.

$$
Q_{o u t, t}=\left\{\begin{array}{lc}
Q_{f d, \max }, & Q_{i n, t} \leq Q_{f d, \max } \\
Q_{i n, t}, & Q_{f d, \max }<Q_{i n, t} \leq \min \left(Q_{a q}, Q_{x, t}\right) \\
\min \left(Q_{a q}, Q_{x, t}\right), & Q_{i n, t}>\min \left(Q_{a q}, Q_{x, t}\right)
\end{array}\right.
$$

In order to make the risk calculation more in line with the actual operational situation, the discharge volume in delay time is not affected by the discharge ratio. 
(3) Discharge error

Discharge error mainly refers to the difference of discharge capacity caused by the error of discharge capacity curve and the operation of discharge facilities, which is simulated by normal distribution, and the random number $\lambda$ conforms to $N\left(1, \sigma^{2}\right)$. Variance $\sigma^{2}$ can be analyzed by the actual discharge data of the reservoir (Diao and Wang 2010), then the actual discharge of each period is:

$$
Q_{\text {out }, t}^{*}=\lambda Q_{\text {out }, t}
$$

\subsubsection{Risk analysis model}

Based on the pre-discharge scheme in section 1.2, considering the probability that the water level of the reservoir at the end of the effective forecast period exceeds the FLWL caused by three uncertain factors: runoff prediction error $q$, dispatching delay time $t_{z}$ and discharge capacity error $x$, the risk analysis model is as follows:

$$
P(Z)=P\left[Z^{Q T}\left(q, t_{z}, x\right)>Z_{x}\right]
$$

Where $Z^{Q T}$ is the water level in the end of the effective forecast period, which is affected by $q, t_{z}$ and $x$.

\subsubsection{Risk model solution}

According to the water balance equation in section 1.2.1, under the different conditions of operating water level point $\left(Z_{i}\right)$ and discharge ratio $\left(\alpha_{j}\right)$, the water level in the end of forecast period after discharge according to the actual inflow $\left(Q_{i n, t}^{*}\right)$ and actual discharge $\left(Q_{\text {out, }}^{*}\right)$ in each period can be calculated, which is recorded as $Z_{i, j}^{Q T}$.

Monte Carlo method is used to conduct $N$ simulations in the forecast period. At the same time, in order to reduce the impact of errors such as water level storage capacity curve on the calculation 
of risk rate, it is necessary to determine the upper and lower floating limits of FLWL $\left(Z_{x, \max }\right.$ and $\left.Z_{x, \min }\right)$ according to the data and actual operation, and calculate the risk rate $\left(P_{i, j}\right)$ of operating water level point $\left(Z_{i}\right)$ under the condition of discharge ratio $\left(\alpha_{j}\right)$ with membership function, which is:

$$
\begin{gathered}
\theta_{n}\left(Z_{i, j}^{Q T}\right)= \begin{cases}1, & Z_{i, j}^{Q T}>Z_{x, \max } \\
\frac{Z_{i, j}^{Q T}-Z_{x, \text { min }}}{Z_{x, \text { max }}-Z_{x, \min }}, & Z_{x, \min }<Z_{i, j}^{Q T}<Z_{x, \max } \\
0, & Z_{i, j}^{Q T}<Z_{x, \min }\end{cases} \\
P_{i, j}=\frac{\sum_{n=1}^{N} \theta_{n}\left(Z_{i, j}^{Q T}\right)}{N} \times 100 \%
\end{gathered}
$$

Where $\theta_{n}\left(Z_{i, j}^{Q T}\right)$ is membership of $Z_{i, j}^{Q T}$ in simulation n.

The risk rate calculation process is shown in Fig. 2.

\subsection{Determination of optimal scheme in flood free period}

The rise of water level in flood free period can bring two effects: firstly, the increase of water head and the increase of power generation benefit; Secondly, the risk of water level exceeding the flood limit water level at the end of pre-discharge period increases. At the same time, in order to deal with the increasingly frequent extreme flood events, this paper selects three indicators of power generation benefit, discharge ratio and risk rate to establish an index-set and uses the weighted Topsis method to solve.

\subsubsection{Index-set with power generation benefit, discharge ratio and risk rate}

The first step is to count the runoff of multi-year flood season. The period from the beginning of each sub-season of the flood season to the flood rising point is taken as the calculation period. If there is no flood in the sub-season, the whole sub-season is taken as the calculation period. The calculation method of enhanced power generation benefit $\left(E_{i}\right)$ corresponding to the operating 
water level point $\left(Z_{i}\right)$ is as follows:

$$
E_{i}=\sum_{n=1}^{Y}\left(E\left(Z_{i}, n\right)-E\left(Z_{x}, n\right)\right) / Y
$$

Where $Y$ is total years of data, $E\left(Z_{i}, n\right)$ and $E\left(Z_{x}, n\right)$ are total power generation calculated by the runoff series of year $\mathrm{n}$ based on $Z_{i}$ and $Z_{x}$.

Thus, an index-set with power generation benefit, discharge ratio and risk rate can be established, which includes $N \times M$ group schemes. The relationship between the three is shown in Fig. 3. The solid lines in different colors in the left figure represent the monotonous relationship between risk rate and power generation benefit under different discharge ratios. The smaller the water discharge ratio, the higher the corresponding risk ratio under the same power generation benefit. In the right figure, red represents the high-risk area corresponding to the decision-making of power generation benefit and discharge ratio, and blue represents the low-risk area.

In order to consider the flood control demand, the membership degree $\theta_{n}\left(Z_{x}\right)$ of FLWL is calculated according to the membership function in Section 2.3.3 and taken as the risk threshold. The schemes with risk rate higher than the risk threshold are screened out as inferior schemes. Assuming that screened-out schemes are $m$ groups, the remaining scheme sets are $A=\left(a_{x, y}\right)_{(N \times M-m) \times 3}$, which is:

$$
A=\left[\begin{array}{ccc}
a_{1,1} & a_{1,2} & a_{1,3} \\
a_{2,1} & a_{2,2} & a_{2,3} \\
\mathbf{M} & \mathbf{M} & \mathrm{M} \\
a_{N \times M-m, 1} & a_{N \times M-m, 2} & a_{N \times M-m, 3}
\end{array}\right]
$$

\subsubsection{Weighted Topsis method}

Topsis normalizes the decision matrix, then multiplies the value in the column by the relative weight to determine the best and worst value in each column, and defines them as the positive ideal solution (PIS) scheme and negative ideal solution (NIS) scheme respectively. Finally, calculate the 
relative proximity between each scheme and the ideal solution and rank them to select the optimal scheme (Singaraju et al, 2022). It is a simple, intuitive and reasonable decision-making method.

After establishing the scheme set, firstly normalize each index in the index-set, which is

$$
r_{x, y}=\frac{a_{x, y}-x_{\min , y}}{x_{\max , y}-x_{\min , y}}
$$

Secondly, the weight of each decision-making type is determined by the combination of subjective and objective weighting method. Given $\omega_{y}$ is the weight of index $y$, and $\sum_{y=1}^{n} \omega_{y}=1$, we use the combination of analytic hierarchy process (AHP) and entropy weight method (Dong et al, 2021) to obtain $\omega_{y}$, and the steps are as follows:

(1) Construct the relative importance matrix $B$ of each index type;

(2) Solve the maximum eigenvalue of matrix $B$ and the corresponding eigenvector, and transform each component of the eigenvector into the weight of each evaluation index under AHP, which is:

$$
C_{y}=\frac{\xi_{y}}{\sum_{y=1}^{3} \xi_{y}}
$$

(3) Calculate the entropy of each index:

$$
H_{y}=-\frac{1}{\ln (N \times M-m)} \sum_{x=1}^{N \times M-m} a_{x, y} \ln a_{x, y}
$$

(4) Calculation of entropy weight of each index according to:

$$
h_{y}=\frac{1-H_{y}}{3-\sum_{y=1}^{3} H_{y}}
$$

(5) The final weight of each index is obtained by combining AHP and Entropy Weight Method:

$$
\omega_{y}=\frac{C_{y} \cdot h_{y}}{\sum_{y=1}^{3} C_{y} \cdot h_{y}}
$$


Next, PIS and NIS are determined. Given $a^{+}$the most preferred scenarios and $a^{-}$is the least preferred scenarios, which are:

$$
\left\{\begin{array}{l}
a^{+}=\left\{\max \left(\mathrm{r}_{i, 1} \cdot \omega_{1}\right), \min \left(\mathrm{r}_{i, 2} \cdot \omega_{2}\right), \min \left(\mathrm{r}_{i, 3} \cdot \omega_{3}\right)\right\} \\
a^{-}=\left\{\min \left(\mathrm{r}_{i, 1} \cdot \omega_{1}\right), \max \left(\mathrm{r}_{i, 2} \cdot \omega_{2}\right), \max \left(\mathrm{r}_{i, 3} \cdot \omega_{3}\right)\right\}
\end{array}\right.
$$

Finally calculate the closeness degree $\left(C_{x}^{+}\right)$between each scheme and PIS:

$$
C_{x}^{+}=\frac{D_{x}^{-}}{D_{x}^{-}+D_{x}^{+}}
$$

Where $D_{x}^{+}$and $D_{x}^{-}$are respectively the distance of scheme $x$ from PIS and NIS.

$$
D_{x}^{+}=\sqrt{\sum_{y=1}^{3}\left[\omega_{y}\left(a_{x, y}-a_{y}^{+}\right)\right]^{2}} \text { and } D_{x}^{-}=\sqrt{\sum_{y=1}^{3}\left[\omega_{y}\left(a_{x, y}-a_{y}^{-}\right)\right]^{2}}
$$

Sort the schemes according to the size of closeness degree, and the scheme with the largest posting schedule is the best one.

\section{Case study}

\subsection{Overview of the study area and data}

Yujiang River is the largest tributary of the West River system in the Pearl River Basin, originating in Guangnan County, Yunnan Province. Youjiang reservoir is not only the multi-year regulating reservoir but the important flood control project in the whole Yujiang River Basin. Therefore, Youjiang reservoir was selected as a case study in this paper. The main characteristic parameters are shown in Table 1. Youjiang reservoir has relatively complete rainfall forecasting, runoff forecasting system and real-time operation system, in which runoff forecasting adopts rolling forecasting mode: Once a day, hour by hour for the next seven days., and runoff forecasting accuracy within one day meets the requirements of use and can be used as the effective forecast period of flood forecast. 


\subsection{Result of flood season segmentation}

Rainstorm generally occurs in June-August in the Yujiang River Basin, and the largest floods in past years mainly occur in July-August. The beginning and ending time of flood season are May 20 and September 30 respectively. The study divides flood season according to circular distribution method, fuzzy statistical test method and fuzzy set analysis method, and results of each method are shown in Fig. 4-6.

The orange dots in Fig. 4 is the time distribution of each historical flood when considering the peak and the blue dot is the time distribution of each historical flood when the peak is not considered. In Fig. 5, the black line is the membership function, the red line is the selected membership threshold, and the red dot is the intersection of the threshold and the membership function, representing the segmentation node. In Fig. 6, the black line is the empirical membership function, the blue line is the fitted membership function and the red line is the selected membership threshold.

Based on the rainfall data of the control area of Youjiang Station in Yujiang River Basin, it is considered that the result of fuzzy statistical test method is more practical. Therefore, the segmentation is determined on the basis of fuzzy statistical test method result in ten days. The results of each method and the final segmentation are shown in Table 2.

\subsection{Calculation of operating water level in flood free period}

Flood season of Youjiang station is divided into 4 sub-seasons. According to the design flood data and the actual operation of Youjiang station, FLWL in each sub-season and the safe discharge are determined, and the upper limit of operating water level in sub-season can be obtained and discretized according to the calculation formula of Section 1.2. FLWL, safe discharge, upper limit of operating water level and the discrete accuracy of each sub-season are shown in Table 3.

FLWL in the fourth sub-season is equal to the normal water level, so it is not considered to raise the operating water level during the fourth sub-season. 


\subsection{Risk factor identification}

The normal distribution curves of errors in each period are fitted according to the forecast data and observed data. The normal distribution frequency curves at $0 \mathrm{~h}, 6 \mathrm{~h}, 12 \mathrm{~h}$ and $18 \mathrm{~h}$ are shown in Fig. 7. The grey bar chart shows the probability distribution density of error samples in each range, and the red line is a fitting normal distribution density curve.

The forecast runoff, observed runoff and time-interval error distribution selected in each period are shown in Fig. 8. Fig. 8a, $8 \mathrm{~b}$ and $8 \mathrm{~b}$ belong to the first, second and third sub-season respectively. The black line is the observed runoff and the blue line is the forecast runoff. The color box diagram represents the normal distribution of errors in each period. The absolute relative error value of the total water volume of the third period forecast data is less than $20 \%$, therefore these can be used as calculation samples of risk rates for each sub-season.

According to the operation data of the power station, the discharge error approximately meets $\lambda \sim N\left(1,0.05^{2}\right)$. Youjiang reservoir has sound regulation and forecast system, and the minimum, most likely and maximum values of delay time of operation are determined as $0 h, 0 h$ and $1 h$ respectively according to the experience of operation experts. The trigonometric distribution function is:

$$
f(t)= \begin{cases}2(1-t), & 0 \leq t \leq 1 \\ 0, & t<0, t>1\end{cases}
$$

\subsection{Calculation of risk rate and determination of optimal scheme}

Set discharge ratio $\alpha=(0.1,0.2, \ldots, 1)$, at the same time, according to the error of water level storage capacity curve of Youjiang River, wind and waves and other factors, the fluctuation range of FLWL in each period is set as $\left(Z_{x}-0.1, Z_{x}+0.1\right)$, and the maximum number of Monte Carlo simulation is 5000. Based on the risk rate calculation method in Section 2.3, the risk rate of each operating water 
level point in each period under different discharge ratio is calculated. According to the calculation method of power generation benefit in section 2.4.1, the operating water level is transformed into power generation benefit. The results of each period are shown in Fig. 9, in which $P$ is the risk rate, $E$ is the power generation benefit and $\alpha$ is the discharge ratio. It can be seen from the figure that the risk rate is in direct proportion to the benefit and in inverse proportion to the discharge ratio.

Combined with the membership function of water level, the risk threshold of each sub-season is 0.5, therefore the index-set of each sub-season is established and solved by Section 2.4 weighted Topsis method after the schemes at risk rate of more than $50 \%$ are screened. The weight calculation and optimal scheme of each sub-season are shown in Table 4 and 5. $H$ represents the lifting head corresponding to power generation benefit $E$.

\section{Discussion}

\subsection{Significance of optimal scheme}

According to the weighted Topsis solution method, the benefit, discharge and risk rate caused by water level rise are comprehensively considered in the optimal scheme, which means that this scheme not only reduces water abandonment, but also improves the operational benefit of the power station, and avoids the high risk caused by water level rise. Based on the flood season operation rules of Youjiang River, the runoff of Youjiang River in the flood season from 2013 to 2017 are used for inspection. Compared with the way of maintaining water level at FLWL, the benefit increased and waste water reduced in each year by the optimal scheme is shown in Table 6 .

The operation process in flood season in 2017 is shown in Fig. 10, in which the black line represents the water level process, the green line represents the inflow process, the blue line represents the outflow process, the red dotted line represents FLWLs, and the purple dotted line represents the raised water level. There are three floods in flood season, of which the first needs pre-discharge, and risk rate and other indicators are shown in Table 7.

The above results show that compared with the operational scheme of maintaining FLWL, the 
power generation benefit of this method is increased by $1.57 \%$ and the operation waste water is reduced by $5.42 \%$ in 2017 . When there is a flood in the flood season, this method can effectively pre-discharge, and the risk rate is only increased by $5 \%$, which is far lower than risk threshold. If there is no flood, there is no need to discharge, which can facilitate the operation of reservoir water storage after the flood season.

\subsection{Impact of risk factors on risk rate}

In section 2.4.2, the risk rate is comprehensively affected by three risk factors. Now multiple combinations of risk factors are set to study the impact on the change of risk rate when the discharge ratio is 1, which is shown in Fig. 11.

The basic laws analyzed from the above diagram are as follows:

(1) When the risk rate is low, the integration risk rate is higher than the combined risk rate of various factors, and the impact of discharge error on the risk rate is higher than that caused by delay time of operation.

(2) When the risk rate is high, the integration risk rate is lower than the single factor risk rate of runoff prediction error and the combined risk rate of runoff forecast error and delay time of operation. This is because when the discharge error is simulated with normal distribution, the water level storage capacity curve usually has convexity, and the discharge error makes the range of water level decrease at the end of the forecast period larger than the range of rise.'

Fig. 12 is a schematic diagram of the impact of discharge error subject to normal distribution on the water level at the end of the forecast period. Where, $V_{m}$ is the reservoir capacity at the end of the forecast period without considering the discharge error, $V_{m, \min }$ and $V_{m, \max }$ are the minimum and maximum capacity at the end of the forecast period when considering the discharge error respectively. Since the discharge error meets the normal distribution, the absolute value of the difference between $V_{m \text {,min }}$ and $V_{m}$ and the difference between $V_{m \text {,max }}$ and $V_{m}$ is equal when the 
number of simulation time is large enough. However, because the water level storage capacity curve is convex, the deviation of the water level at the end caused by the initial water level rise $\left(\Delta Z_{1}\right)$ is less than that caused by the water level decrease $\left(\Delta Z_{2}\right)$, which is reflected in the risk rate and the discharge error will reduce the risk rate at high risk.

\subsection{Influence of weight on scheme selection}

The weight is calculated according to the AHP method in section 2.4. The relatively important weight matrix, weight calculation results and optimal scheme of indexes in each sub-season are as follows:

$$
\begin{aligned}
& B_{1}=\left[\begin{array}{ccc}
1 & 1 / 3 & 2 \\
3 & 1 & 1 \\
1 / 2 & 1 & 1
\end{array}\right] \\
& B_{2}=\left[\begin{array}{lll}
1 & 1 & 1 / 2 \\
1 & 1 & 1 / 2 \\
2 & 2 & 1
\end{array}\right] \\
& B_{3}=\left[\begin{array}{ccc}
1 & 1 & 1 / 2 \\
1 & 1 & 1 / 2 \\
2 & 2 & 1
\end{array}\right]
\end{aligned}
$$

The weight determined by AHP and the optimal scheme are shown in table 8 and 9, and the weight determined by entropy weight method and the optimal scheme are shown in table 10 and 11.

The above results show that:

(1) In the first sub-season, the AHP method takes too much account of the impact of benefits, and since the entropy weight method determines the index from the confusion between the index values, it is hard to represent the characteristics of the risk rate and discharge ratio index itself. In the scheme selection of the third sub-season, the discharge ratio index is excessively considered, and the risk rate of the selected scheme is improved, which is not conducive to the flood control. In 
comparison, the combination of AHP and entropy weight method is more conducive to the selection of the optimal scheme.

(2) In Topsis decision-making, the increase of a certain weight does not always mean that the optimal scheme is biased towards this index, which is also related to the normalization method.

\section{Conclusions}

In order to effectively coordinate the benefits and risks of reservoir operation, the benefits of power generation, the discharge in the forecast period and the risk rate of exceeding FLWL at the end of the forecast period should be fully considered. This study proposes a dynamic water level decisionmaking system in flood free period. Firstly, historical data and various flood season staging methods are used to divide the flood season into multiple sub-seasons, and then the maximum inflow process in the effective forecast period of flood forecast in each sub-season is selected. According to this inflow process, the upper limit of operating water level in the flood free period of each sub-season is determined based on the reservoir discharge capacity, and the operating water level points and discharge ratio are discretized, Then the multi-order Monte Carlo Markov chain (MCMC) and Monte Carlo method are used to calculate the risk rate. Then, the scheme set is established by the three variables of power generation benefit, discharge ratio and risk rate. Finally, the weighted Topsis method is used to determine the optimal scheme. The method is applied to Youjiang reservoir in Yujiang River Basin, and the following conclusions are drawn:

(1) Combined with the discharge in the forecast period, the reservoir operating water level has a certain lifting space in the flood free period, which can effectively reduce the waste of resources.

(2) In the discharge process in the forecast period, runoff forecast error and discharge error are the two factors that have the greatest impact on the risk rate, and the multi-order MCMC method effectively reflects the relationship between the adjacent periods of runoff forecast error, and its simulation process is closer to the reality. 
(3) Topsis with the combination of AHP and entropy weight method can fully consider the characteristics of power generation benefit, discharge ratio and risk rate, and it is effective to select the optimal solution from the set of non-inferior schemes.

This study provides a new method for determining the operating water level in the flood free period of the reservoir in the flood season, and fully considers the influence of power generation benefit, discharge in the forecast period and risk rate. In the future research, a variety of normalization and weight methods can be used to solve the scheme so as to realize the rapid determination and application of the scheme under the different needs of decision makers.

\section{Declarations}

\section{Conflicts of interest/Competing interests}

The author has no conflicts to declare that are relevant to the content of this article.

\section{Authors' contributions}

Mu Zhenyu: Conceptualization, Methodology, Formal analysis. Ai Xueshan: Conceptualization, Methodology, Writing - review \& editing. Ding Jie: Conceptualization, Methodology, Writing review \& editing. Huang Kui: Data curation, Funding acquisition. Chen Senlin: Writing - review \& editing, Funding acquisition. Guo Jiajun: Investigation, Software. Dong Zuo: Writing - review \& editing, Software.

\section{Acknowledgments}

This study is financially supported by the National Natural Science Foundation of China [Grant No. 91647119] and science and technology project of Guangxi Power Grid Corporation [Grant No. 0400002020030103DD00134]. 


\section{Reference:}

Alizadeh MJ, Kavianpour MR, Kisi O, Nourani V (2017) A new approach for simulating and forecasting the rainfall-runoff process within the next two months. J. Hydrol. 548, 588-597. https://doi.org/10.1016/j.jhydrol.2017.03.032.

Beurton S and Thieken AH (2009) Seasonality of floods in Germany / Saisonnalite des crues en Allemagne. Hydrological Sciences Journal, 54(1), pp. 62-76. https://doi.org/10.1623/hysj.54.1.62.

Carpenter TM, Georgakakos KP (2001) Assessment of Folsom lake response to historical and potential future climate scenarios: 1. Forecasting, J. Hydrol, 249, 148-175. https://doi.org/10.1016/S0022-1694(01)00417-6.

Chen S, Wang S, Wang G, Geng N, Xu W, Leng A (2003) Determination of relative dependence function of flood season by direct fuzzy statistic test. Advances in Science and Technology of Water, 1:5-7+69. DOI: 0067647(2003)01-0005-03

Chen Y and Li J and Chen A (2021) Does high risk mean high loss: Evidence from flood disaster in southern China[J]. Science of the Total Environment, 785: 147127-147127.

Diao Y, Wang B (2010) Risk analysis of flood control operation mode with forecast information based on a combination of risk sources. Sci China Tech Sci, 53: 1949-1956, doi: 10.1007/s11431-010-3124-3.

Dong Q, Wang X, Wang J, Fu C (2007) Application of fractal theory in the stage analysis of flood seasons in Three Gorges reservoir. Resources and Environment in the Yangtze Basin, 3: 400-404. doi: 1004-8227( 2007) 03-0400-05.

Dong Z, Ni X, Chen M, Yao H, Jia W, Zhong J, Ren L (2021) Time-varying Decision-making Method for Multiobjective Regulation of Water Resources. Water Resources Management: An International Journal - Published for the European Water Resources Association (EWRA), 35(10), 3411-3430. https://doi.org/10.1007/s11269021-02901-8.

Fang B, Guo SL, Wang SX, Liu P, Xiao Y (2007) Non-identical models for seasonal flood frequency analysis. Hydrol Sci J 52(5):974-991. 10.3969/j.issn.1000-0852.2007.05.002.

Fang B, GUO S, Guo F, Liu P (2007) Identification of Flood Seasonality by Circular Distribution Method. JOURNAL OF CHINA HYDROLOGY, 27(5), 7-11. https://doi.org/10.3969/j.issn.1000-0852.2007.05.002. 
Hadfield J D (2010) MCMC Methods for Multi-Response Generalized Linear Mixed Models: The MCMCglmm

R Package. Journal of Statistical Software, 33(2), 1-22. https://doi.org/10.18637/jss.v033.i02.

Jiang Q, Wang T, Wang Z, Fu Q, Zhou Z, Zhao Y, Dong Y (2018) HHM- and RFRM-Based Water Resource System Risk Identification. Water Resources Management: An International Journal - Published for the European Water Resources Association (EWRA), 32(12), 4045-4061. https://doi.org/10.1007/s11269-0182037-y.

Li X, Zhang Y, Tong Z (2021) Study on Multi-Objective Cooperative Decision Making of Reservoir Flood Control Water Level[J/OL]. Journal of Hydroelectric Engineering:1-11. http://kns.cnki.net/kcms/detail/11.2241.TV.20211101.1853.004.html.

Li, N, Guo S, Xiong F, Wang J, Xie Y (2022) Comparative Study of Flood Coincidence Risk Estimation Methods in the Mainstream and its Tributaries. Water Resour Manage, 1-16. https://doi.org/10.1007/s11269-02103050-8.

Liu X, Guo S, Liu P, Chen L, Li X (2011) Deriving Optimal Refill Rules for Multi-Purpose Reservoir Operation. Water Resources Management: An International Journal - Published for the European Water Resources Association (EWRA), 25(2), 431-448. https://doi.org/10.1007/s11269-010-9707-8.

Liu Y, Ji C, Wang Y, Zhang Y, Hou X, Xie Y (2022) Quantifying streamflow predictive uncertainty for the optimization of short-term cascade hydropower stations operations, J. Hydrol, 605, 127376. https://doi.org/10.1016/j.jhydrol.2021.127376.

Lu Q, Zhong P, Xu B, Zhu F, Ma Y, Wang H, Xu S (2020) Risk analysis for reservoir flood control operation considering two-dimensional uncertainties based on Bayesian network. Journal of Hydrology, 589. https://doi.org/10.1016/j.jhydrol.2020.125353.

Moser P, Wiechers G, Schmidt S, Monteiro JGMS, Goetheer E, Charalambous C, Saleh A, van der Spek M, Garcia S (2021) ALIGN-CCUS: Results of the 18-month test with aqueous AMP/PZ solvent at the pilot plant at Niederaussem - solvent management, emissions and dynamic behavior. International Journal of Greenhouse Gas Control, 109. https://doi.org/10.1016/j.ijggc.2021.103381.

Pan Z, Liu P, Gao S, Feng M, Zhang Y (2018) Evaluation of flood season segmentation using seasonal exceedance probability measurement after outlier identification in the Three Gorges Reservoir. Stochastic Environmental 
Research and Risk Assessment, 32(6), 1573-1586. https://doi.org/10.1007/s00477-018-1522-4.

Reichstein M, Riede F, Frank D (2021) More floods, fires and cyclones - plan for domino effects on sustainability goals. Nature, 592(7854), 347-349. http://dx.doi.org/10.1038/d41586-021-00927-x.

Singaraju S, Hernandez EA, Uddameri V, Pasupuleti S (2022) Prioritizing Groundwater Monitoring in Data Sparse Regions Using Atanassov Intuitionistic Fuzzy Sets (A-IFS). Water Resources Management 32 (4): 1483-99. Accessed January 16. doi: 10.1007/s11269-017-1883-3.

Wang Y, Wang B, Fan H, Hou G, Li Y (2020) Study on Flood Season Staging of Different Stations in Xijiang River Based on Fuzzy Set Analysis. Pearl River, 41(4), 8-14. https://doi.org/10.3969/j.issn.10019235.2020.04.002.

Wang Z, Wang Y, Hu S (2007) Effective fuzzy cluster method for dividing reservoir flood season, Advances in Water Science, 4: 580-585. doi: 001-6791（2007） 04-0580-06.

Wu Z, Hu C, Wang B, Liu H (2006) Risk analysis on limited water level of reservoirs in flood season and flood control system in midstream and downstream of Yellow River. JOURNAL OF HYDRAULIC ENGINEERING, 37(6), 641-648. https://doi.org/10.3321/j.issn:0559-9350.2006.06.001.

Xu B, Huang X, Mo R, Zhong P, Lu Q, Zhang H, Si W, Xiao J, Sun Y (2021) Integrated real-time flood risk identification, analysis, and diagnosis model framework for a multireservoir system considering temporally and spatially dependent forecast uncertainties, J. Hydrol, 600, 126679. https://doi.org/10.1016/j.jhydrol.2021.126679.

Xu B, Huang X, Zhong P, Wu Y (2020) Two-Phase Risk Hedging Rules for Informing Conservation of Flood Resources in Reservoir Operation Considering Inflow Forecast Uncertainty. Water Resour Manage 34, 27312752. https://doi.org/10.1007/s11269-020-02571-y.

Yao H, Dong Z, Jia W, Ni X, Zhu C, Li D (2019) Competitive Relationship between Flood Control and Power Generation with Flood Season Division: A Case Study in Downstream Jinsha River Cascade Reservoirs[J]. Water, 11(11), 2401. https://doi.org/10.3390/w11112401.

Yüksel I (2010) Hydropower for sustainable water and energy development. Renew. Sustain. Energy Rev. 14(1), 462-469. https://doi.org/10.1016/j.rser.2009.07.025.

Yun R, Singh VP (2008) Multiple duration limited water level and dynamic limited water level for flood control, 
with implications on water supply. J Hydrol 354(1-4):160-170.

Zhang Y, Zhang J, Tai Y, Ji C, Ma Q (2021) Stochastic simulation model of forecast errors in the process of reservoir runoff based on IGMM-Copula Journal of Hydraulic Engineering, 52(06):689-699. DOI:10.13243/j.cnki.slxb.20200681.

Zhao T (2013) Study on Reservoir Operation based on Hydrological Forecast: Uncertainty Analysis and Optimization [D]. Tsinghua University.

Zhao T, Cai X, Yang D (2011) Effect of streamflow forecast uncertainty on real-time reservoir operation. Advances in Water Resources, 34(4): 495-504. Doi: 10.1016/j.advwatres.2011.01.004. 
Table 1: Main parameters for the Youjiang reservoir

\begin{tabular}{ccc}
\hline Items & Unit & Youjiang \\
\hline Normal Level & $\mathrm{m}$ & 228 \\
Dead Level & $\mathrm{m}$ & 203 \\
Installed Capacity & $\mathrm{MW}$ & 540 \\
Mean annual runoff & $\mathrm{m}^{3} / \mathrm{s}$ & 263 \\
Maximum generation flow & $\mathrm{m}^{3} / \mathrm{s}$ & 692 \\
Forecast period & $\mathrm{h}$ & 24 \\
\hline
\end{tabular}

Table 2: Segmentations of each method and final selection scheme

\begin{tabular}{cccc}
\hline Methods & Node 1 & Node 2 & Node 3 \\
\hline Circular distribution method & $7 / 19$ & $8 / 26$ & 1 \\
Fuzzy set analysis method & $6 / 30$ & $9 / 19$ & 1 \\
Fuzzy statistical test method & $7 / 4$ & $8 / 12$ & $9 / 7$ \\
Final scheme & $7 / 10$ & $8 / 10$ & $9 / 1$ \\
\hline
\end{tabular}

Table 3: FLWL, safe discharge, upper limit of operating water level and the discrete accuracy

\begin{tabular}{cccccc}
\hline & Unit & 1st & 2nd & 3th & 4th \\
\hline Flood limited water level & $\mathrm{m}$ & 214 & 219.7 & 222.3 & 228 \\
Safety discharge & $\mathrm{m}^{3} / \mathrm{s}$ & \multicolumn{5}{c}{2000} \\
Operating-limited water level & $\mathrm{m}$ & 214.8 & 220 & 223 & $/$ \\
Discretization precision & $\mathrm{m}$ & 0.1 & 0.05 & 0.1 & $/$ \\
\hline
\end{tabular}

Table 4: Index weight of each sub-season

\begin{tabular}{cccc}
\hline & 1st & 2nd & 3rd \\
\hline $\mathrm{E}$ & 0.41 & 0.22 & 0.23 \\
$\alpha$ & 0.37 & 0.31 & 0.37 \\
$\mathrm{P}$ & 0.22 & 0.47 & 0.50 \\
\hline
\end{tabular}

Table 5: Optimal scheme of each sub-season

\begin{tabular}{ccccc}
\hline & Unit & $1 \mathrm{st}$ & $2 \mathrm{nd}$ & $3 \mathrm{rd}$ \\
\hline $\mathrm{E}$ & $10^{\wedge} 8 \mathrm{kWh}$ & 0.15 & 0.04 & 0.06 \\
$\mathrm{H}$ & $\mathrm{m}$ & 0.4 & 0.1 & 0.2 \\
$\alpha$ & $/$ & 0.9 & 0.9 & 0.9 \\
$\mathrm{P}$ & $\%$ & 20 & 6 & 4 \\
\hline
\end{tabular}

Table 6: Benefit increased and waste water reduced in flood season of each year

\begin{tabular}{|c|c|c|c|c|c|c|c|}
\hline \multicolumn{4}{|c|}{ Power generation benefit } & \multicolumn{4}{|c|}{ Waste water } \\
\hline Original & This & Increase & Percentage & Original & This & Reduction & Percentage \\
\hline
\end{tabular}




\begin{tabular}{ccccccccc}
\hline & method & method & amount & increased & method & method & amount & reduction \\
\hline Year & $10^{\wedge} 8 \mathrm{kWh}$ & $10^{\wedge} 8 \mathrm{kWh}$ & $10^{\wedge} 8 \mathrm{kWh}$ & $\%$ & $10^{\wedge} 8 \mathrm{~m}^{3}$ & $10^{\wedge} 8 \mathrm{~m}^{3}$ & $10^{\wedge} 8 \mathrm{~m}^{3}$ & $\%$ \\
2013 & 4.20 & 4.29 & 0.09 & 2.14 & 0 & 0 & 0 & 0 \\
2014 & 7.75 & 7.86 & 0.11 & 1.42 & 1.22 & 1.13 & 0.09 & 7.38 \\
2015 & 8.43 & 8.68 & 0.25 & 2.97 & 4.17 & 3.43 & 0.74 & 17.75 \\
2016 & 4.48 & 4.57 & 0.09 & 2.01 & 0.03 & 0 & 0.03 & 100 \\
2017 & 8.91 & 9.05 & 0.14 & 1.57 & 7.38 & 6.98 & 0.40 & 5.42 \\
\hline
\end{tabular}

Table 7: Comparison of various indicators

\begin{tabular}{cccc}
\hline & Unit & This method & Original method \\
\hline Waste water & $10^{\wedge} 8 \mathrm{~m}^{3}$ & 6.98 & 7.38 \\
Power generation benefit & $10^{\wedge} 8 \mathrm{kWh}$ & 9.05 & 8.91 \\
Risk rate & $\%$ & 6 & 1 \\
\hline
\end{tabular}

Table 8: Weight of each index in each sub-season (AHP)

\begin{tabular}{cccc}
\hline & 1st & 2nd & 3rd \\
\hline $\mathrm{E}$ & 0.49 & 0.25 & 0.25 \\
$\alpha$ & 0.31 & 0.25 & 0.25 \\
$\mathrm{P}$ & 0.20 & 0.50 & 0.50 \\
\hline
\end{tabular}

Table 9: Optimal scheme of each sub-season (AHP)

\begin{tabular}{ccccc}
\hline & Unit & $1 \mathrm{st}$ & 2nd & 3rd \\
\hline $\mathrm{E}$ & $10^{\wedge} 8 \mathrm{kWh}$ & 0.21 & 0.04 & 0.06 \\
$\mathrm{H}$ & $\mathrm{m}$ & 0.6 & 0.1 & 0.2 \\
$\alpha$ & $/$ & 1 & 0.9 & 0.9 \\
$\mathrm{P}$ & $\%$ & 29 & 6 & 4 \\
\hline
\end{tabular}

Table 10: Weight of each index in each sub-season (Entropy weight method)

\begin{tabular}{cccc}
\hline & 1st & 2nd & 3rd \\
\hline $\mathrm{E}$ & 0.26 & 0.29 & 0.31 \\
$\alpha$ & 0.37 & 0.41 & 0.37 \\
$\mathrm{P}$ & 0.37 & 0.30 & 0.32 \\
\hline
\end{tabular}

Table 11: Optimal scheme of each sub-season (Entropy weight method)

\begin{tabular}{ccccc}
\hline & Unit & $1 \mathrm{st}$ & 2nd & $3 \mathrm{rd}$ \\
\hline $\mathrm{E}$ & $10^{\wedge} 8 \mathrm{kWh}$ & 0.05 & 0.02 & 0.03 \\
$\mathrm{H}$ & $\mathrm{m}$ & 0.1 & 0.05 & 0.1 \\
$\alpha$ & $/$ & 0.8 & 0.8 & 0.8 \\
$\mathrm{P}$ & $\%$ & 2 & 22 & 8 \\
\hline
\end{tabular}




\begin{tabular}{|c|c|c|c|}
\hline $\begin{array}{l}\text { Flood season } \\
\text { segmentation }\end{array}$ & $\begin{array}{l}\text { Circular } \\
\text { distribution } \\
\text { method }\end{array}$ & $\begin{array}{l}\text { Fuzzy } \\
\text { statistical } \\
\text { test method }\end{array}$ & $\begin{array}{l}\text { Fuzzy set } \\
\text { analysis } \\
\text { method }\end{array}$ \\
\hline \multicolumn{4}{|l|}{1} \\
\hline $\begin{array}{l}\text { Decision set } \\
\text { establishment }\end{array}$ & \multicolumn{3}{|c|}{$\begin{array}{l}\text { (1) Select historical samples of sub-seasons. } \\
\text { (2) Calculate the maximum operating water level in } \\
\text { each sub-season. } \\
\text { (3) Discrete operating water level and discharge ratio. }\end{array}$} \\
\hline \multirow{5}{*}{ Risk analysis } & \multicolumn{3}{|c|}{ (1) Risk factor identification. } \\
\hline & $\begin{array}{l}\text { Multi-order } \\
\text { MCMC }\end{array}$ & $\begin{array}{l}\text { Normal } \\
\text { distribution }\end{array}$ & $\begin{array}{l}\text { Triangular } \\
\text { distribution }\end{array}$ \\
\hline & & $=--y=-=$ & 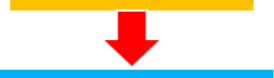 \\
\hline & $\begin{array}{l}\text { Runoff } \\
\text { forecast errors }\end{array}$ & $\begin{array}{l}\text { Discharge } \\
\text { errors }\end{array}$ & $\begin{array}{l}\text { Delay time of } \\
\text { operation }\end{array}$ \\
\hline & \multicolumn{3}{|c|}{$\begin{array}{l}\text { (2) Risk rate calculation based on membership function } \\
\text { and Monte Carlo method. }\end{array}$} \\
\hline $\begin{array}{l}\text { Determination of } \\
\text { optimal scheme }\end{array}$ & \multicolumn{3}{|c|}{$\begin{array}{l}\text { (1)The weight is determined by AHP and entropy } \\
\text { weight method. } \\
\text { (2)Determining optimal scheme by weighted Topsis. }\end{array}$} \\
\hline
\end{tabular}

Fig. 1: Method frame diagram 


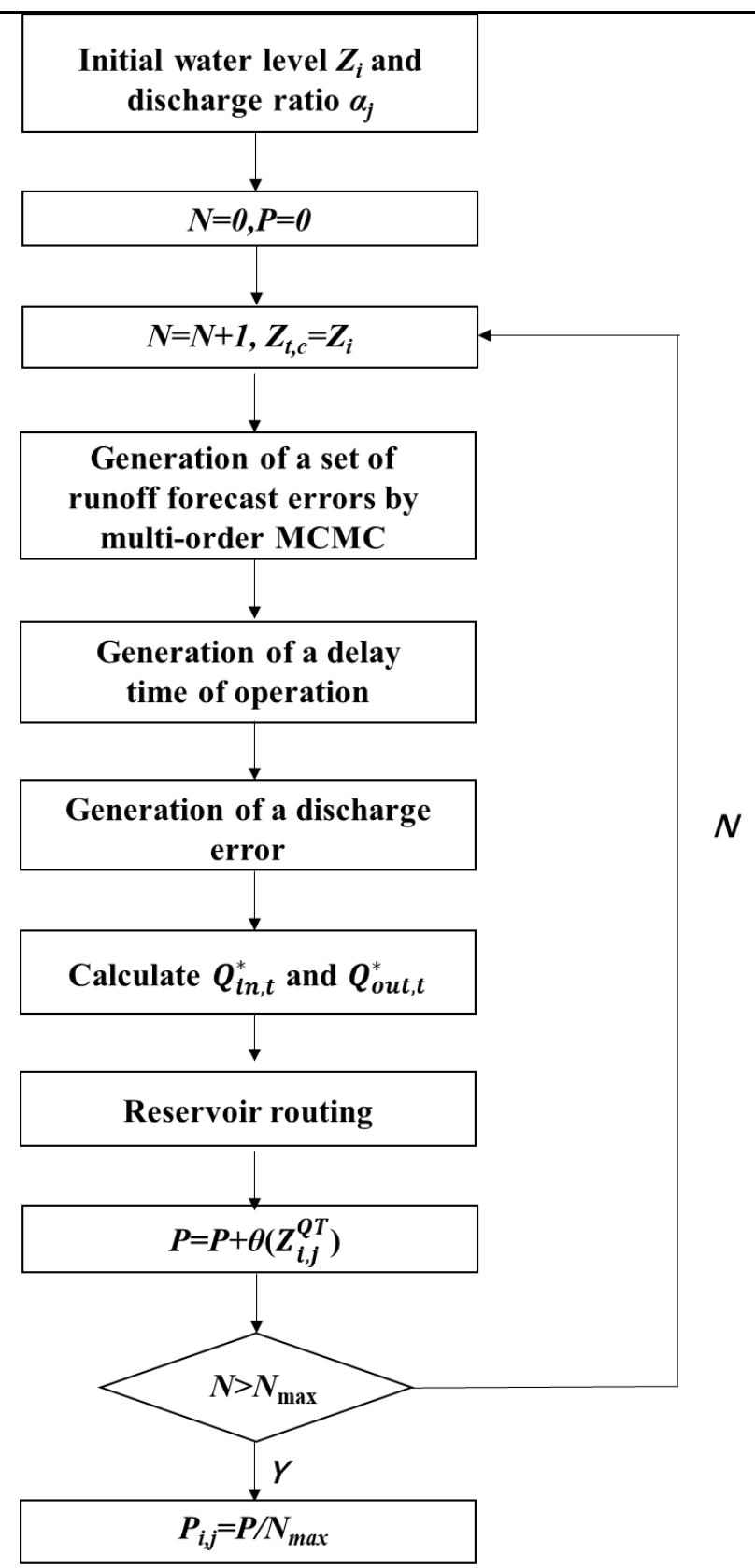

Fig. 2: Risk rate calculation flow chart 


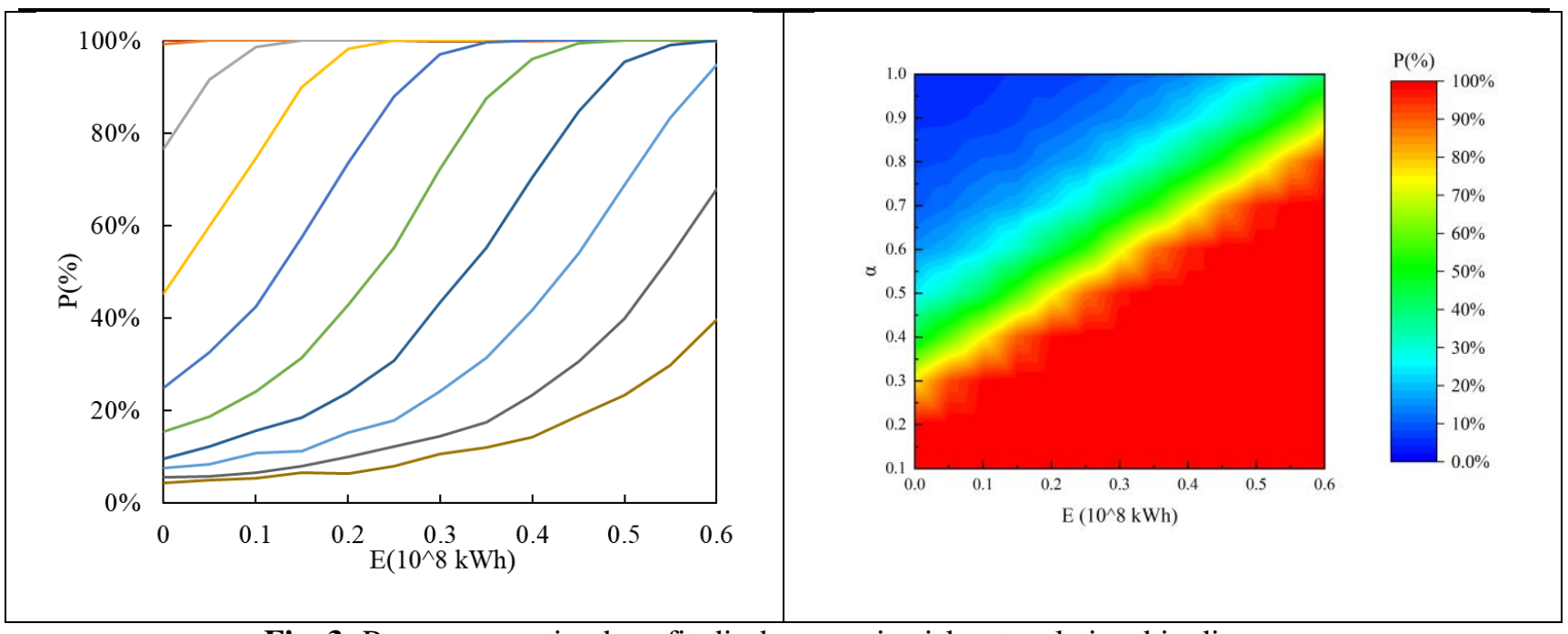

Fig. 3: Power generation benefit-discharge ratio-risk rate relationship diagram

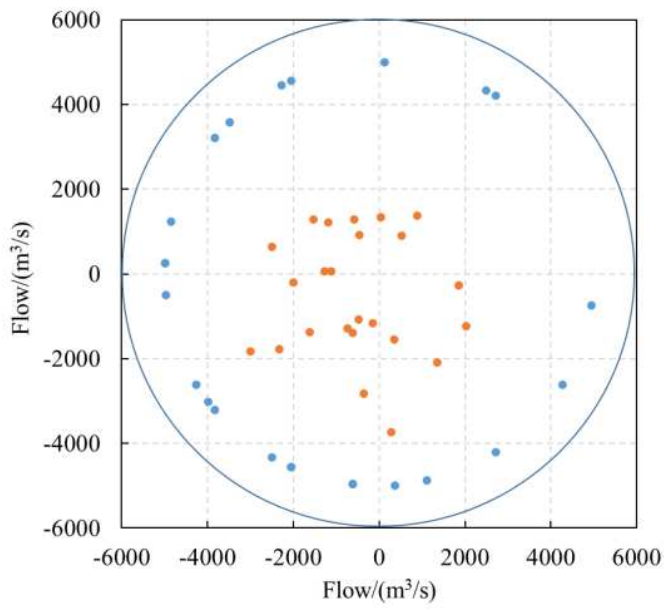

Fig. 4: Circular distribution method

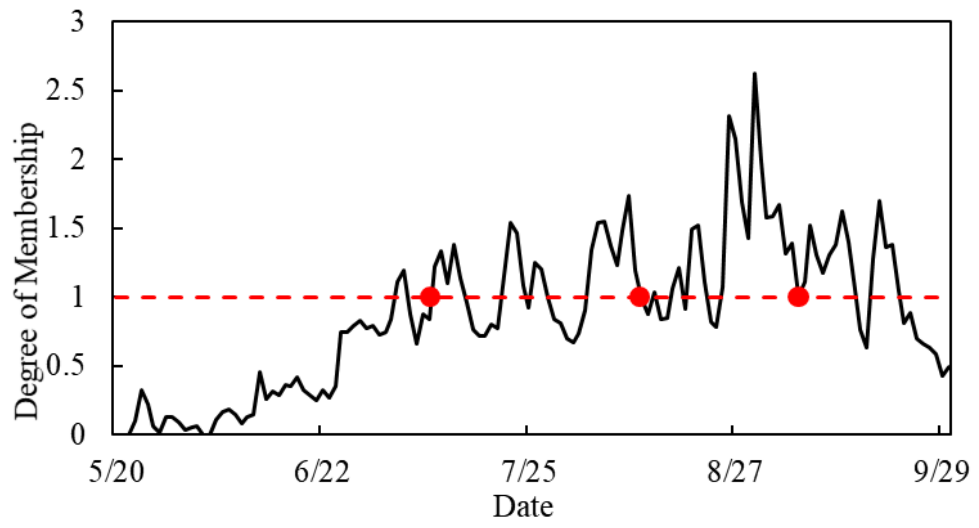

Fig. 5: Fuzzy statistical test method 


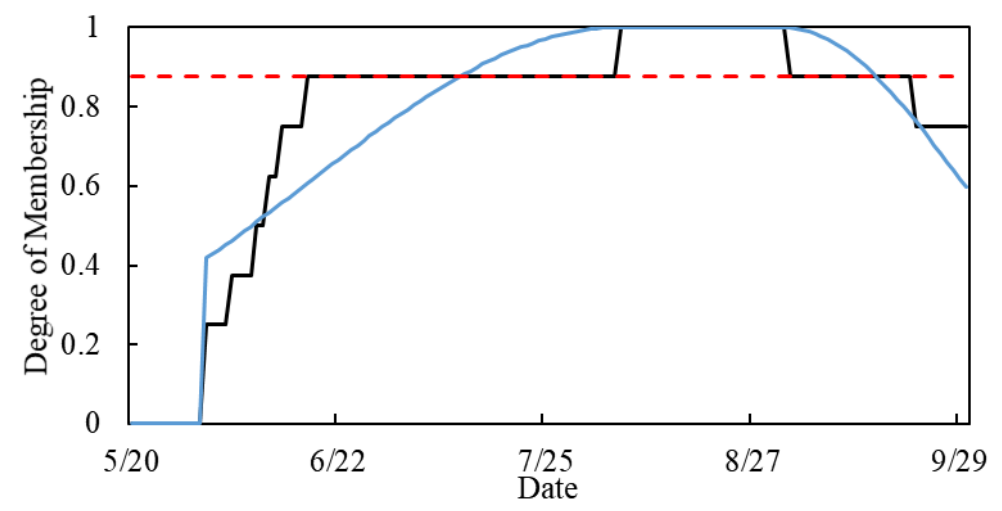

Fig. 6: Fuzzy set analysis method

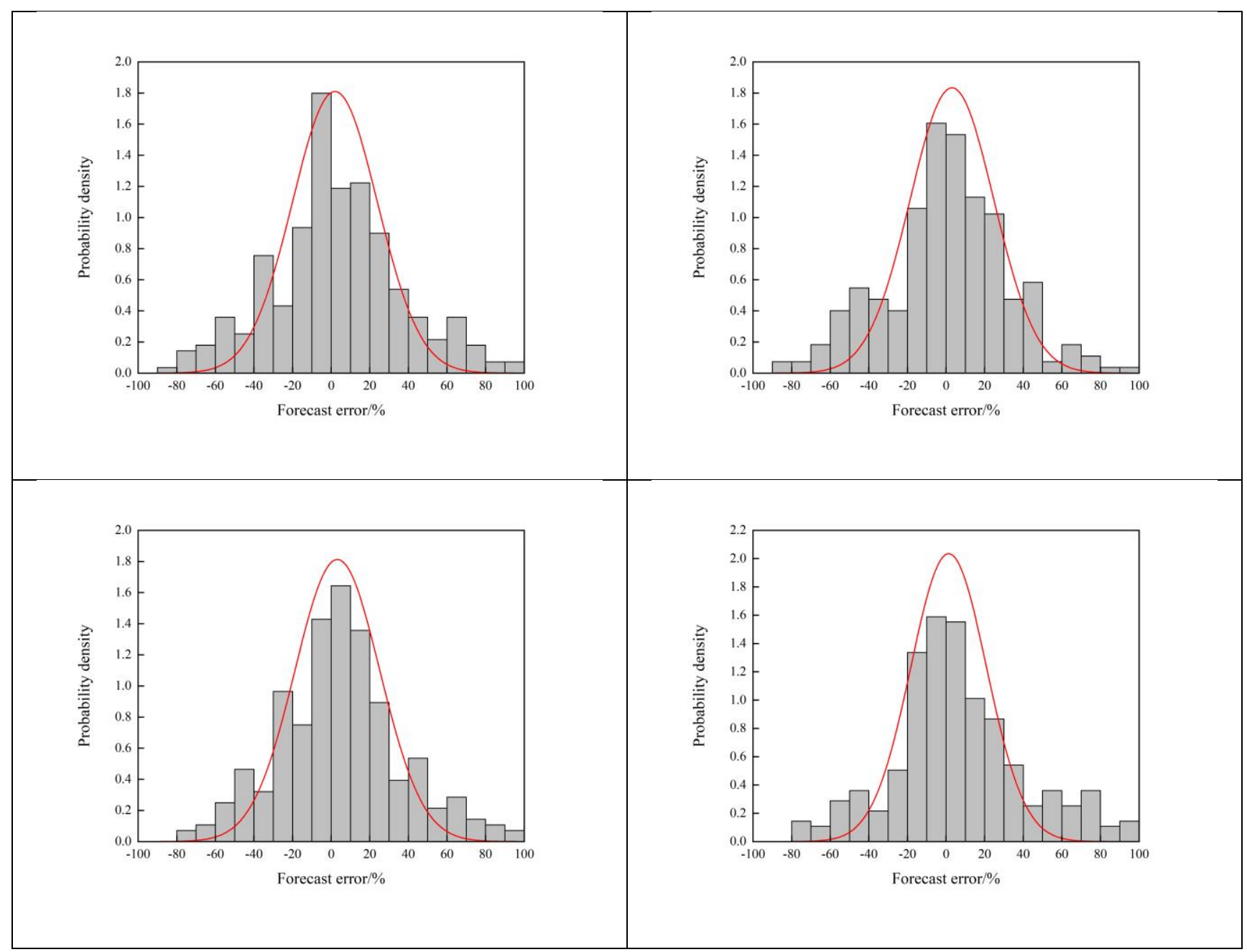

Fig. 7: Sample probability distribution density curve and fitted normal distribution density curve 


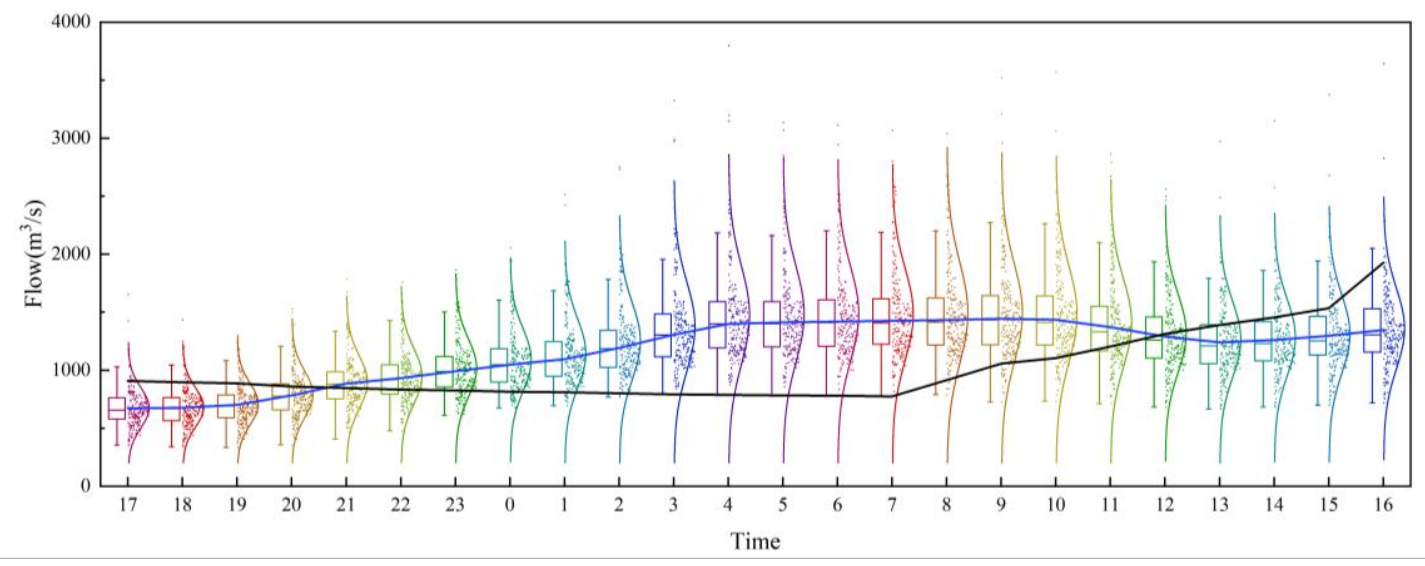

Fig. 8a: Sample selection and period error distribution in the first sub-season

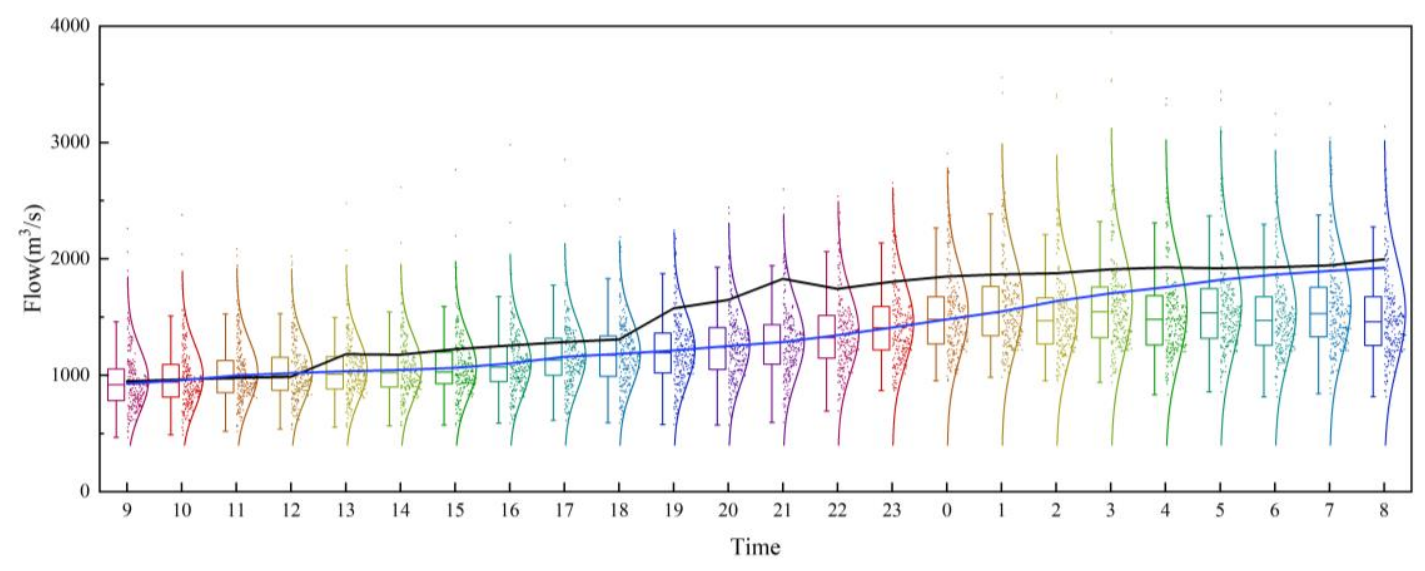

Fig. 8b: Sample selection and period error distribution in the second sub-season

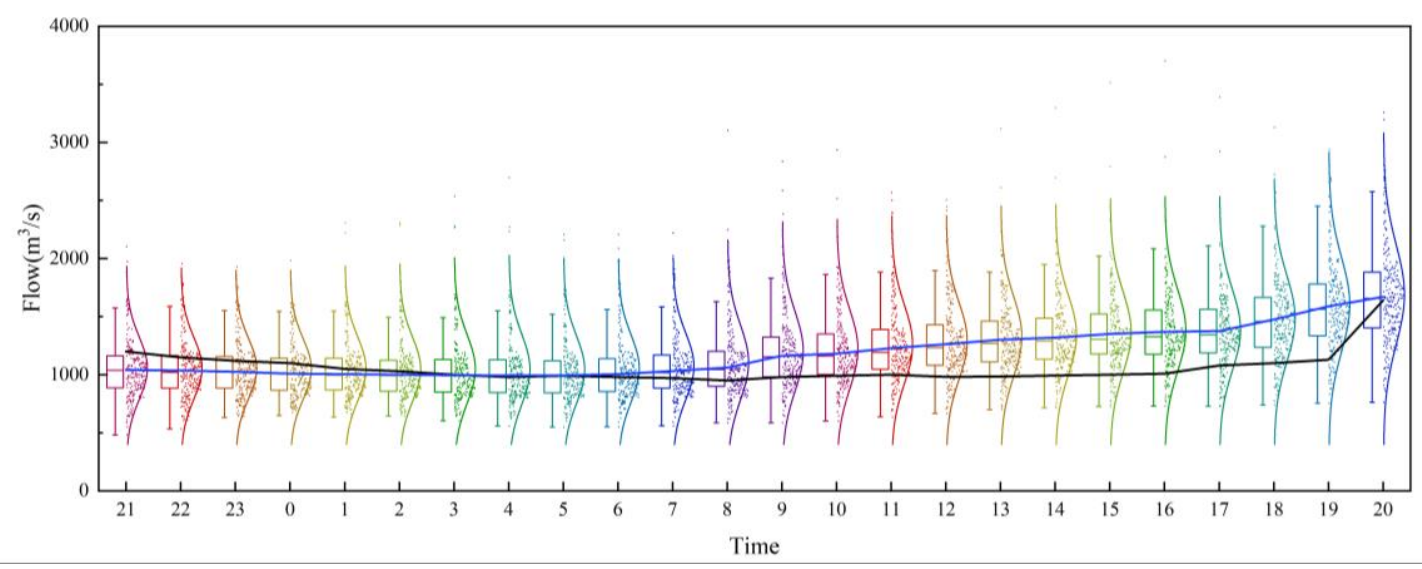

Fig. 8c: Sample selection and period error distribution in the third sub-season

Fig. 8: Samples selected in each sub-season and period error distribution 


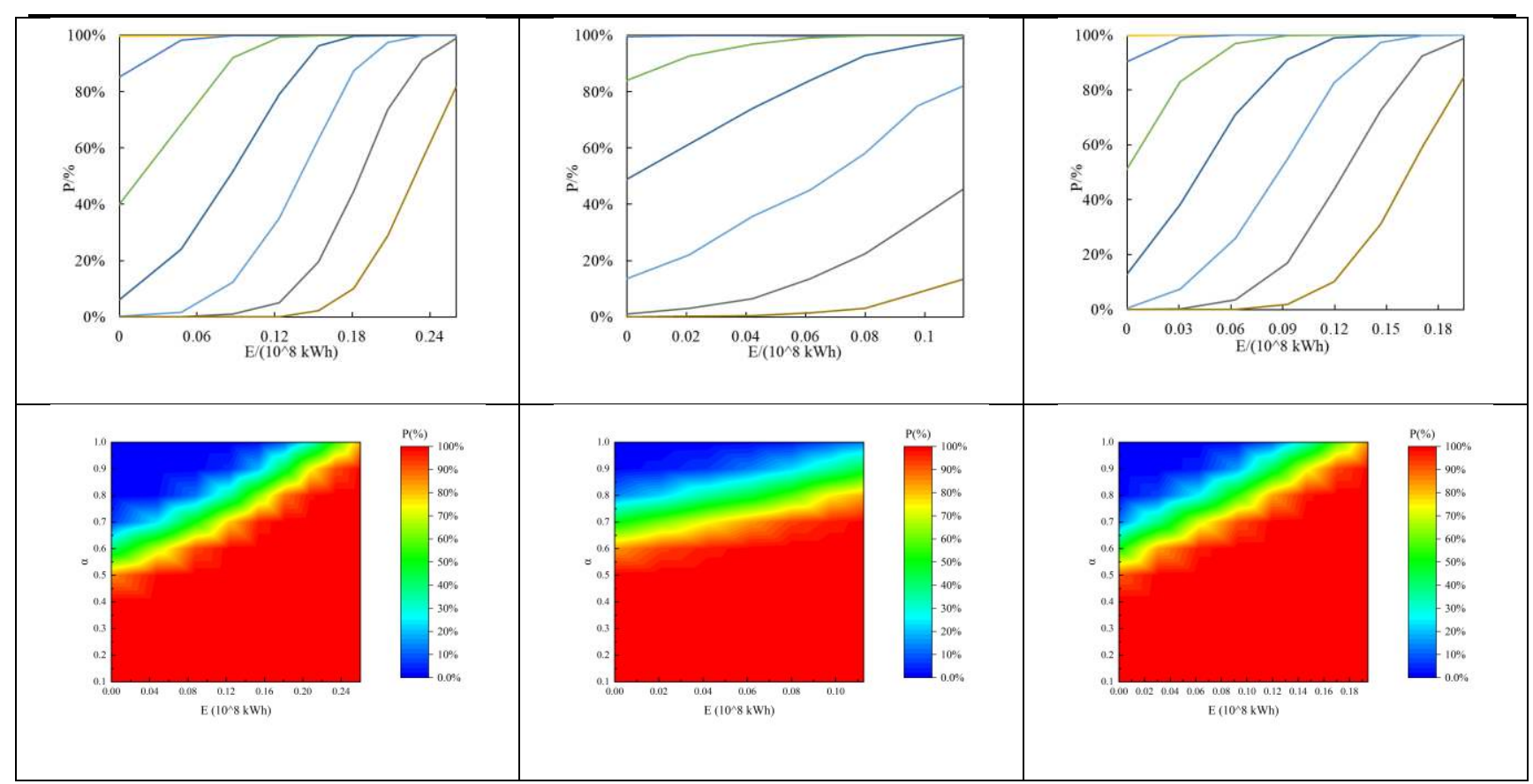

Fig. 9: Relationship between power generation benefit, discharge ratio and risk rate of each sub-season

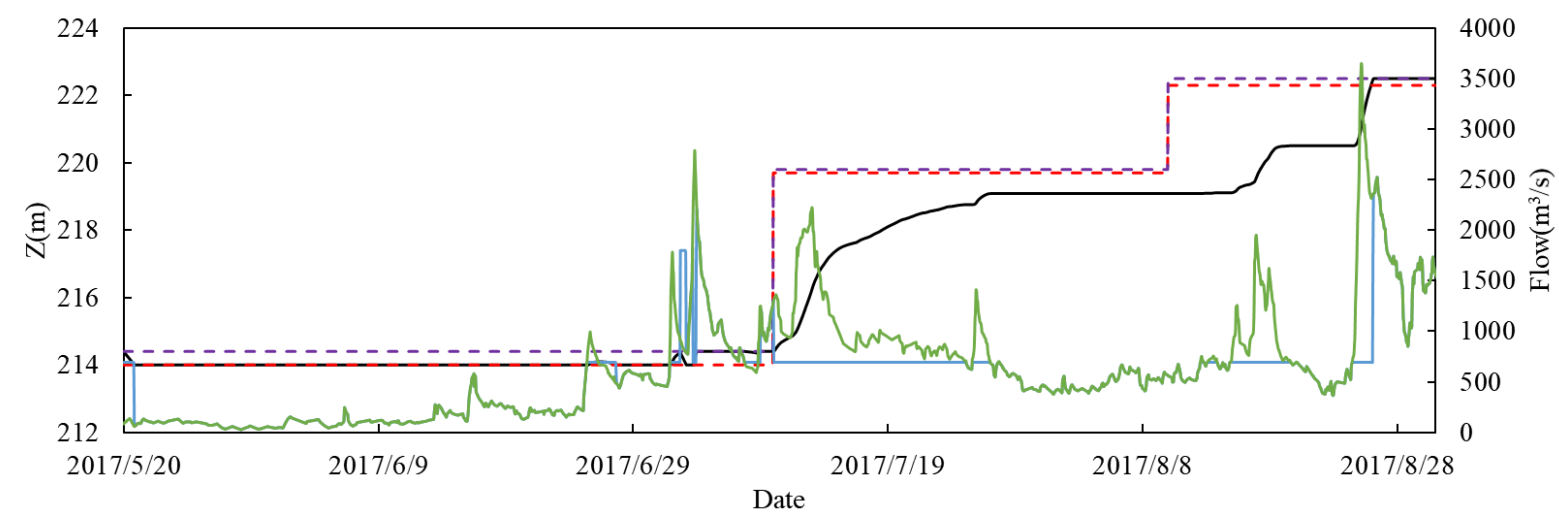

Fig. 10: Operation process in flood season in 2017

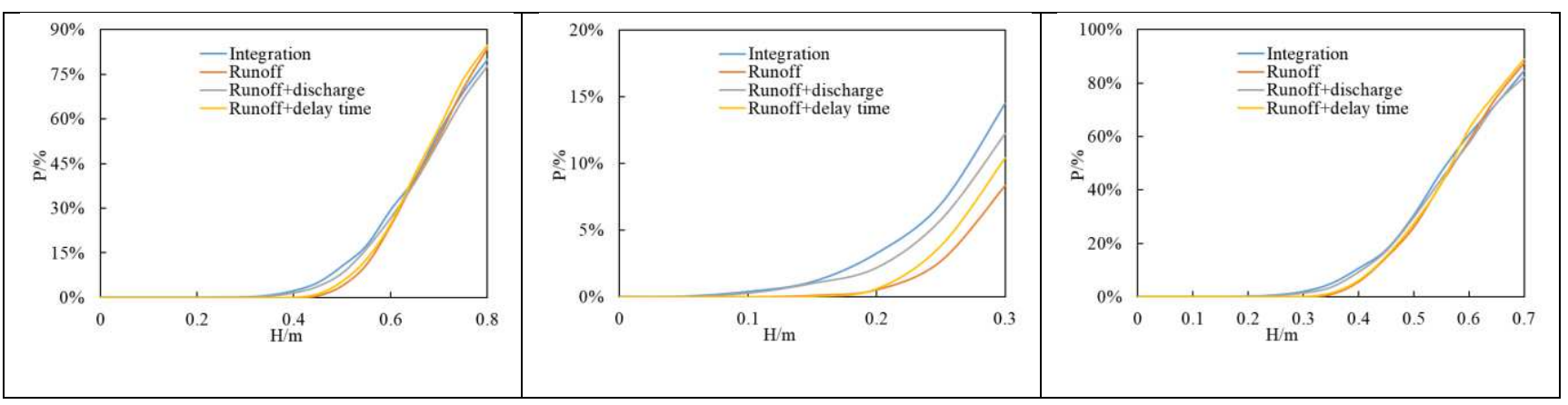

Fig 11: Diagram of relationship between lifting head and risk rate under different combinations 


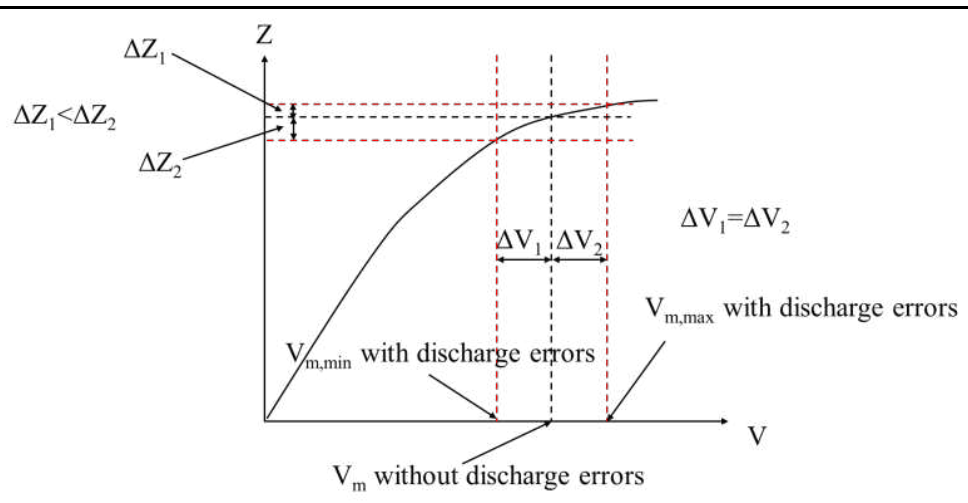

Fig. 12: Influence of discharge error in accordance with normal distribution 